\title{
Stereological analysis of acute lung injury
}

\author{
M. Ochs
}

\begin{abstract}
Acute lung injury is associated with a variety of histopathological alterations, such as oedema formation, damage to the components of the blood-air barrier and impairment of the surfactant system. Stereological methods are indispensable tools with which to properly quantitate these structural alterations at the light and electron microscopic level. The stereological parameters that are relevant for the analysis of acute lung injury are reviewed in the present article.
\end{abstract}

KEYWORDS: Acute lung injury, microscopy, morphometry, stereology

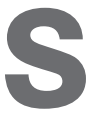
tereology is the method of choice with which to obtain quantitative structural data in microscopy. It is therefore an essential tool for making statistically valid comparisons in experimental studies on acute lung injury (ALI), e.g. when the effects of different treatment modalities are tested. The present article describes the stereological parameters that are relevant for the assessment of the degree of injury in ALI. For an introduction to and a more comprehensive treatment of stereology, the reader is referred to the literature [1-6] and to the article by NYENGAARD and GUNDERSEN [7] in the present issue of the European Respiratory Review (ERR). General aspects of lung stereology have been reviewed recently $[8,9]$.

\section{DEFINITION AND EPIDEMIOLOGY OF ALI}

The clinical entity of ALI in its most severe form, acute respiratory distress syndrome (ARDS), was originally described by ASHBAUGH et al. [10] in 1967. The most widely adopted current definition of ALI and ARDS is based on the recommendations given by the American European Consensus Conference (AECC) committee [11]. ALI and ARDS are defined as a syndrome of acute and persistent lung inflammation with increased vascular permeability characterised by bilateral chest infiltrates, hypoxia (partial pressure of arterial oxygen/fraction of inspired oxygen $<40 \mathrm{kPa}(<300 \mathrm{mmHg})$ for ALI and $<26.7 \mathrm{kPa}$ $(<200 \mathrm{mmHg})$ for ARDS) and exclusion of a cardiogenic cause (no left atrial hypertension). For the purposes of the present article, the term ALI also includes ARDS as the severe end of the spectrum of ALI. While the AECC definition is simple to apply in the clinical setting and it reflects the fact that the severity of clinical lung injury varies, its major disadvantage is that it does not contain any information on the underlying cause [12]. The development of ALI is associated with a variety of clinical disorders, including direct pulmonary injury (e.g. from pneumonia or aspiration) and indirect pulmonary injury (e.g. from trauma or sepsis) $[12,13]$. A special form of ALI manifests as primary graft dysfunction in lung transplantation. Its main cause is ischaemia (I)/reperfusion (R) injury [14-16].

Recent data suggest that ALI is more common than initially thought, with crude incidences at $59-79$ per 100,000 person-yrs in a US population [17]. Earlier data ranged $\sim 5-30$ per 100,000 person-yrs (reviewed in [18, 19]). Currently reported mortality rates are $\sim 40 \%[17,18]$.

\section{HISTOPATHOLOGICAL ASPECTS OF ALI}

The histopathological features of ALI have been is, however, a rather unspecific term. Diffuse alveolar damage can be divided into an early exudative phase, lasting for $\sim 1$ week, and a later fibroproliferative phase in the second and third weeks [20-24]. The exudative phase is characterised by interstitial and intra-alveolar oedema, intra-alveolar haemorrhage, neutrophil accumulation and hyaline membranes consisting of fibrin, plasma proteins and surfactant. At the ultrastructural level, swelling and necrosis of capillary endothelial cells and type I alveolar epithelial cells are noted, leading to a denudation of the basal lamina. In the fibroproliferative phase, organisation with proliferation of type II alveolar epithelial cells (cuboidal metaplasia), alveolar septal thickening and finally fibrosis are present. It is generally believed that the histopathological features of ALI reflect a typical response pattern to lung injury irrespective of the underlying cause. However, subtle but important differences, e.g. between ALI resulting from direct or indirect lung injury, are detectable by more detailed analysis involving electron microscopy and stereology [25]. collectively termed diffuse alveolar damage. This
CORRESPONDENCE

M. Ochs

Institute of Anatomy

Experimental Morphology

University of Bern

Baltzerstrasse 2

CH-3012 Bern

Switzerland

Fax: 41316313807

E-mail: ochs@ana.unibe.ch

\section{SUPPORT STATEMENT}

The present work was supported by the Deutsche Forschungsgemeinschaft (DFG Oc-23/7-3 and 0c-23/8-1) 
The clinical symptoms of ALI are a direct consequence of severe damage to the blood-air barrier and subsequent protein-rich (permeability) pulmonary oedema [26, 27]. In ALI resulting from direct lung injury, alveolar epithelial cells are the first to be altered, while ALI resulting from indirect lung injury begins with alteration of capillary endothelial cells. Intra-alveolar oedema, together with other factors, such as reactive oxygen and nitrogen species and neutrophil elastase, leads to alterations in the pulmonary surfactant system, which, in turn, lead to the decreased compliance that can be observed in ALI patients [28-34]. Thus, the components of the blood-air barrier and the surfactant system are primary targets in ALI and are therefore the structures that should be addressed when assessing ALI using stereology.

Although an animal model that unequivocally mimics key aspects of human ALI is still lacking [13], there are several animal models available that have proven useful in the study of either direct or indirect pulmonary injury [35]. In these animal models of ALI, the structural changes lead to significant disturbances of functional performance. It is thus important to quantitate them properly, i.e. by means of stereology.

\section{STEREOLOGICAL ASSESSMENT OF ALI \\ Lung preparation for microscopy}

The following two criteria must be met in order to perform proper lung stereology.

\section{Adequate fixation and processing}

Lung preparation protocols, from fixation over dehydration and embedding to sectioning, need to be controlled very carefully to avoid alterations of the tissue dimensions. It is impossible to perform good stereology with bad material. Since the fine structural details of the constituents of the alveolar blood-air barrier and the various surfactant forms are beyond the resolution limit even of advanced light microscopy, specimen preparation for transmission electron microscopy is a prerequisite for a complete stereological analysis of ALI. Subtle but functionally important alterations would go undetected at the light microscopic level, e.g. only by electron microscopy is it possible to distinguish permeability oedema due to primary blood-air barrier injury in ALI from the lesions in hydrostatic oedema [36-39] and to analyse intra-alveolar surfactant subtype alterations [40-43]. Primary chemical fixation "from behind" by controlled vascular perfusion with a glutaraldehyde-containing fixative followed by a phospholipid-stabilising protocol is the method of choice when subsequent stereological analysis of oedema and surfactant has to be performed [44-49].

\section{Systematic uniformly random sampling in a cascade sampling design}

Stereology is basically a sampling theory and, thus, the steps to obtain the tissue samples that are finally analysed at the microscope are an integral part of a stereological study. Final results can only be unbiased when the sampling was such; the most efficient way to achieve this is known as systematic uniformly random sampling. In experimental studies, the starting point for sampling, and the end-point for data analysis, should always be the total lung volume ( $V$ (lung)). This can be measured by fluid displacement recorded by weighing [50] or, preferably, by the Cavalieri method [51, 52]. Starting from there, a cascade of sampling steps is followed, ideally in a fractionator design, via the light microscopic to the electron microscopic level (described by NYENGAARD and GUNDERSEN [7] in the present issue of the ERR). Thus, global parameters, such as the volumes of parenchyma ( $V$ (par, lung)) and nonparenchyma ( $V$ (nonpar, lung)) or surface areas of alveolar epithelium ( $S$ (alvepi)) and capillary endothelium (S(capendo)), can be estimated (see table 1 ).

\section{Pulmonary oedema}

Typically, the development of pulmonary oedema follows a sequence of fluid accumulation in various compartments in the lung $[22,53,54]$. First, fluid appears in the connective tissue compartment around bronchi and larger blood vessels, the peribronchovascular space. Then, fluid enters the alveolar septal interstitium and, eventually, the alveolar space after the two interstitial compartments are filled (fig. 1). As a global indicator of fluid accumulation, the lung wet/dry ratio is commonly used. However, this method does not give any information about the compartment in which oedema occurs. In contrast, a stereological approach allows for quantitative lung oedema analysis in its preserved microorganisation and location within the organ, as well as for the dissection of the particular contributions of peribronchovascular, septal and intra-alveolar oedema. This approach has been used successfully in various animal models of I/R injury, where it has been demonstrated that intra-alveolar oedema is the functionally most significant $[42,55-57]$. These studies have also shown that oedema assessment by stereology better reflects the functional status of the lung than does wet/dry ratio analysis.

Recommended parameters for the stereological analysis of pulmonary oedema are the total volume of oedema ( $V$ (oed, lung)) and volumes of intra-alveolar $(V$ (alvoed, oed)), septal ( $V$ (sepoed, oed)) and peribronchovascular ( $V$ (pbvoed, oed)) oedema (table 1$)$.

\section{Lung cell types}

The number and mean size of a given cell type is essential information when hyperplasia and/or hypertrophy of these cells are to be quantitated, a typical case being type II alveolar epithelial cells in ALI (fig. 2). This cell type is usually more resistant to injury than the type I cell $[20,23,58]$ and serves as the progenitor cell for the regeneration of the adult alveolar epithelium [59]. It is, however, important to note that the stereological analysis of certain cell types can sometimes cause problems when pathological alterations, e.g. the occurrence of intermediate cells expressing both type I and type II cell markers during the regeneration of the alveolar epithelium after lung injury [60], make their classification difficult. After all, it is only possible to count what is identifiable [61].

Recommended parameters for the stereological analysis of the cellular composition of the alveolar septum are the total cell volume per lung $(V$ (cell, lung)), the total cell number per lung ( $N$ (cell, lung)), the number-weighted mean cell volume ( $\bar{v} N($ cell $))$ and the volume-weighted mean cell volume $(\bar{v} V($ cell $))$ (table 1$)$.

\section{Blood-air barrier}

The blood-air barrier has to face a bioengineering dilemma in that it has to be both thin and strong $[62,63]$. According to Fick's law of diffusion, oxygen flow across a tissue barrier is directly proportional to the cross-sectional surface area and inversely proportional to the thickness of the barrier. The human lung, with 


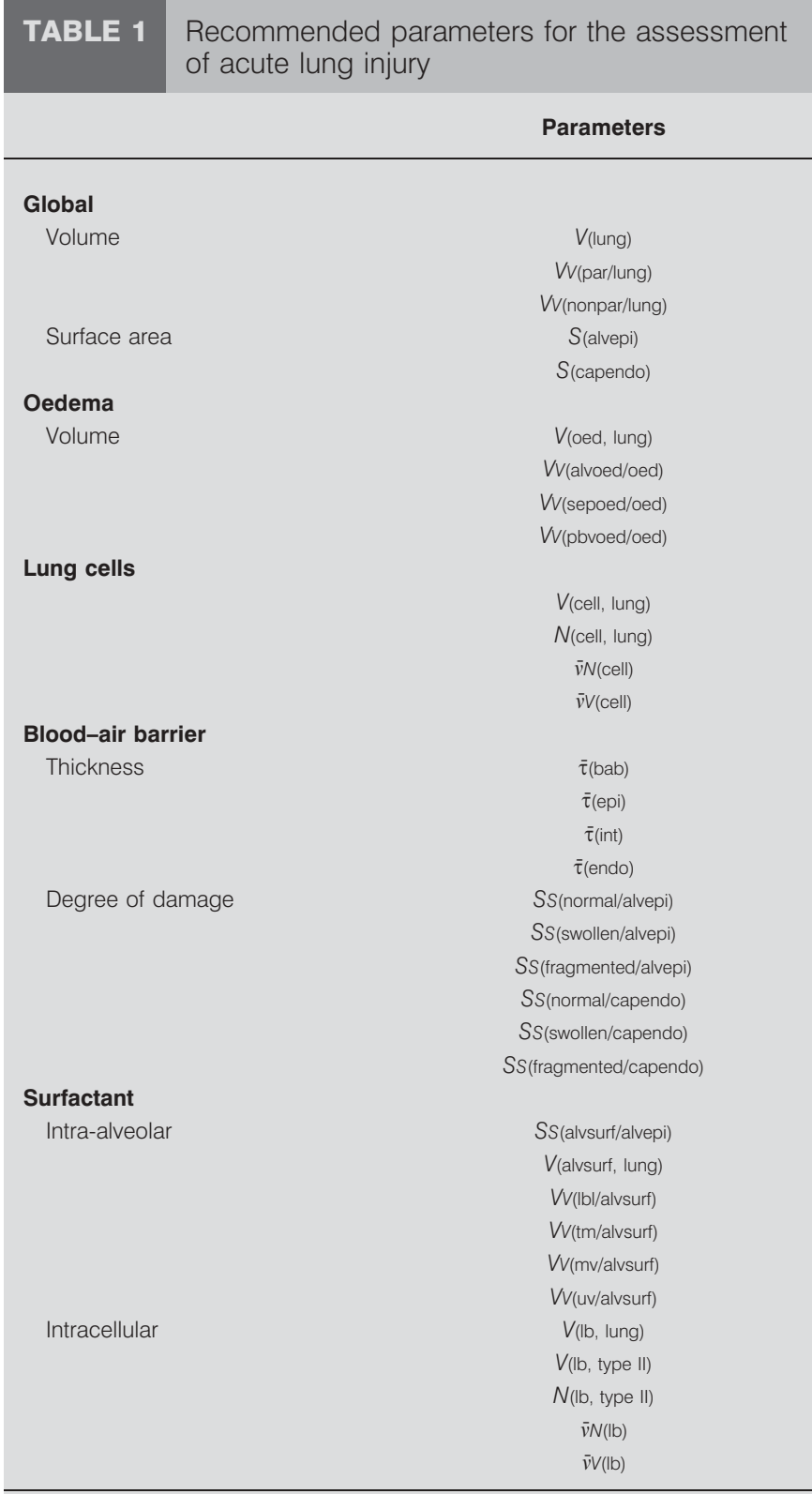

After estimation of total lung volume (V(lung)) with the Cavalieri method, which can easily be integrated into the sampling procedure, point-counting in a cascade-sampling design estimates all necessary subcomponent volumes (VV) from which total volumes $(V$ can be derived by multiplication by the reference volume. For surface area $(S)$, intersection counting is used accordingly. The number $(N)$ is estimated by disector counting. Number-weighted mean volume $(\bar{v} N)$ is estimated either by local methods, e.g. the nucleator or rotator, or globally by $V / N$. The volume-weighted mean volume $(\bar{v} V)$ is estimated by pointsampled intercepts. If both the number-weighted and the volume-weighted mean volumes are known, information on the size distribution of particles can be derived, since $\bar{v} V=\bar{v}_{N} \cdot\left(1+C V_{N}^{2}(v)\right)$, where $C V$ is coefficient of variation and $\bar{v}$ is mean volume. Arithmetic mean barrier thickness $(\bar{\tau})$ is estimated with a combination of point and intersection counting. Ss: surface fraction; par: parenchyma; nonpar: nonparenchyma; alvepi: alveolar epithelium; capendo: capillary endothelium; oed: oedema; alvoed: intra-alveolar oedema; sepoed: septal oedema; pbvoed: peribronchovascular oedema; bab: blood-air barrier; epi: epithelium; int: interstitium; endo: endothelium; alvsurf: intra-alveolar surfactant; Ibl: lamellar body-like forms; tm: tubular myelin; mv: multilamellar vesicles; uv: unilamellar vesicles; Ib: lamellar bodies; type II: type II cell. an alveolar surface area of $\sim 140 \mathrm{~m}^{2}$ and a harmonic mean thickness of the blood-air barrier of $\sim 0.6 \mu \mathrm{m}$, is optimised in that respect [64]. Intra-alveolar and interstitial oedema, as well as oedematous swelling of the alveolar epithelium or capillary endothelium, increase the effective barrier thickness, thereby leading to decreased oxygenation in ALI.

The blood-air barrier consists of the alveolar epithelium, the capillary endothelium and the interstitium in between (fig. 2). The alveolar epithelium is a mosaic of squamous type I cells that line $\sim 97 \%$ of the surface with their thin cell extensions and cuboidal type II cells. Type II cells have the following two main functions: 1) they serve as the cellular source of surfactant and 2) they contribute to the regeneration of the alveolar epithelium under normal and pathological conditions, such as ALI. The capillary endothelium is of the continuous (nonfenestrated) type. At the thin parts of the blood-air barrier, which constitutes over half of the total surface area, the interstitium is reduced to a fused epithelial and endothelial basal lamina. Stereological assessment of the thickness of the blood-air barrier components (alveolar epithelium, interstitium, capillary endothelium) and their degree of damage (normal, swollen, fragmented) has been performed in animal models of I/R injury $[42,55,56]$.

Recommended parameters for the stereological analysis of the blood-air barrier (table 1) are the arithmetic mean thickness of the blood-air barrier $(\bar{\tau}(\mathrm{bab}))$ and its constituents, the alveolar epithelium $(\bar{\tau}($ epi $))$, the interstitium $(\bar{\tau}($ int $))$, and the capillary endothelium $(\bar{\tau}($ endo $))$. For assessment of the degree of damage, the parameters are the surface fractions of normal $(S S($ normal $/ . .)$.$) ,$ swollen $(S S($ swollen/...)) and fragmented (SS(fragmented/...)) alveolar epithelium (SS(.../alvepi)) and capillary endothelium (SS(.../ capendo)), respectively.

\section{Surfactant}

The surfactant system has biophysical (surface tension reduction) and immunomodulatory functions that are essential for normal lung function [31, 65-68]. Thus, surfactant keeps lung alveoli open, dry and clean. Surfactant is composed of $\sim 90 \%$

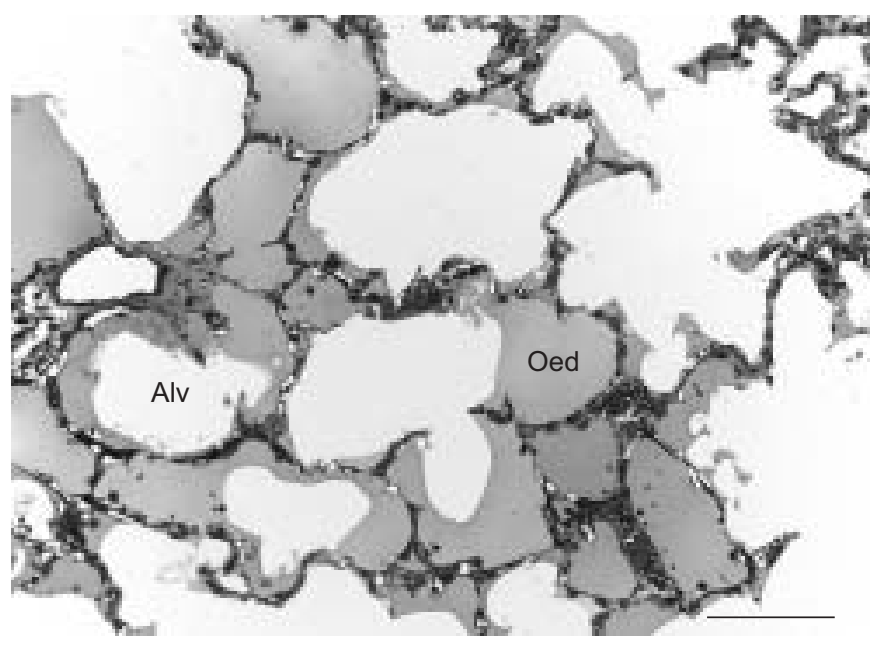

FIGURE 1. Light micrograph from a pig lung subjected to ischaemia/ reperfusion injury. For details about the experiment conditions see [55]. Intraalveolar oedema fluid (Oed) is partly filling alveolar lumina (Alv). Scale bar $=100 \mu \mathrm{m}$. 


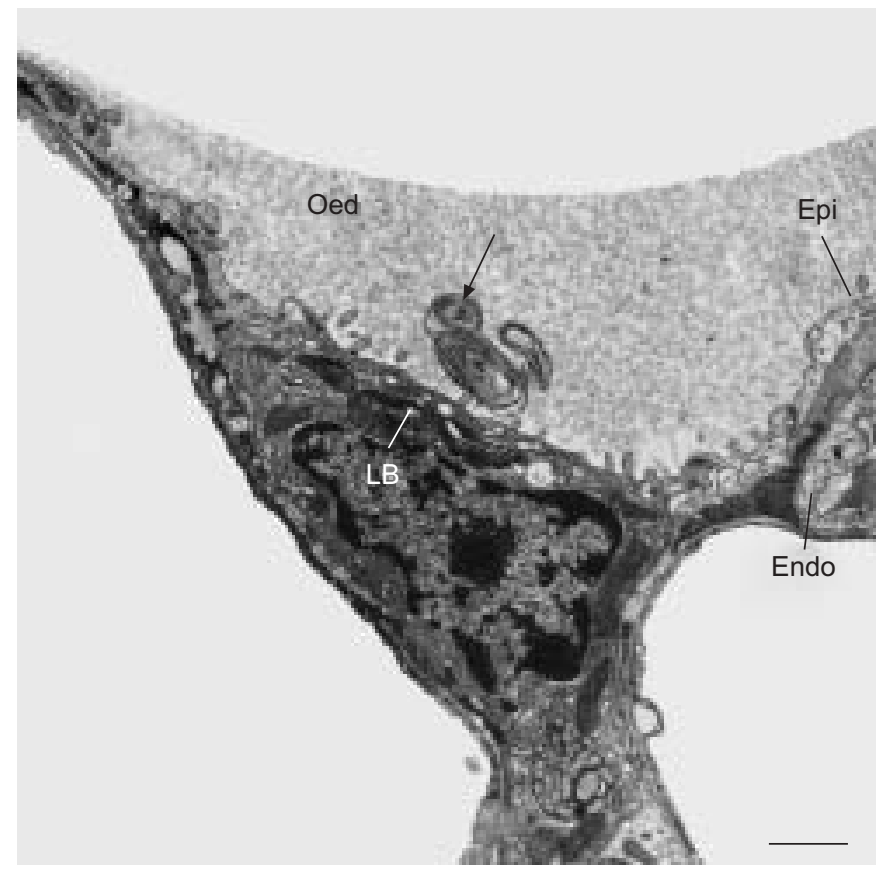

FIGURE 2. Transmission electron micrograph from a rat lung subjected to ischaemia/reperfusion injury. For details about the experimental conditions see $[41,42]$. Three alveolar lumina can be seen, one of which is partly filled with proteinrich oedema fluid (Oed). The alveolar epithelial type II cell contains several lamellar bodies (LB). Intra-alveolar surfactant material (arrow) is present within oedema fluid. The blood-air barrier shows swellings of alveolar epithelial type I (Epi) and capillary endothelial (Endo) cells. Scale bar $=1 \mu \mathrm{m}$.

lipids, mainly saturated phosphatidylcholine, and $\sim 10 \%$ proteins, including the surfactant proteins (SP)-A, SP-B, SP-C and SP-D. Surfactant is also morphologically very complex. Different surfactant subtypes with a highly organised structure that can be distinguished morphologically (by electron microscopy) correspond to different stages in surfactant metabolism.

The alveolar epithelium is lined by a thin fluid layer. Surfactant functions in and on this layer. It is synthesised, stored, secreted and, to a large extent, recycled by type II alveolar epithelial cells [59, 69]. Therefore, an intracellular surfactant pool in type II cells and an intra-alveolar surfactant pool at the surface of the alveolar lining layer, as well as within its hypophase, can be distinguished (fig. 2). Within type II cells, surfactant is stored in lamellar bodies [70,71]. Surfactant material present in lamellar bodies is secreted into the alveolar lumen via exocytosis [72].

Intra-alveolar surfactant consists of several subtypes. After secretion, lamellar body-like forms transform into tubular myelin figures with a unique lattice-like structure. Tubular myelin is considered to be the immediate precursor of the surface film. "Spent" surfactant components are present in the hypophase as small unilamellar vesicles. The major route of surfactant clearance is re-uptake by type II cells. Within type II cells, surfactant material can be either recycled or degraded. Other routes of surfactant clearance include ingestion and lysosomal degradation by alveolar macrophages and clearance via the airways.
As mentioned previously, surfactant inhibition is one of the hallmark events in the pathophysiology of ALI [12, 28, 32-34, 73-75]. Therefore, surfactant analysis is essential when assessing ALI and, in principle, surfactant can be analysed in the following two ways.

\section{Biochemical/biophysical surfactant analysis}

Typically, surfactant analysis is based on material obtained by bronchoalveolar lavage (BAL). This approach allows for biochemical (surfactant composition) and biophysical (surfactant function) analysis. In addition, several other components of the BAL material can be measured, e.g. the cellular composition or inflammatory cytokines. However, only the intra-alveolar surfactant compartment can be harvested by BAL and any topographical information is lost $[67,76]$. Moreover, BAL and the isolation of surfactant material require strictly controlled conditions to avoid experimental error and to make results comparable [77-79]. This is even more true in ALI, when analysis is further complicated by the presence of intra-alveolar oedema fluid in the BAL samples [80]

\section{Morphological surfactant analysis}

An alternative approach to analysing surfactant is by electron microscopy and stereology. It has the great advantage of allowing for the study of the intra-alveolar as well as the intracellular surfactant pool in its natural location and preserved microorganisation (fig. 2) [81]. This approach is perfectly suited for experimental studies.

\section{Analysis of intra-alveolar surfactant}

After differential centrifugation of intra-alveolar surfactant material harvested by BAL, surface active large aggregates (LA), ultrastructurally predominantly corresponding to lamellar body-like forms and tubular myelin, and converted inactive small aggregates (SA), ultrastructurally predominantly corresponding to unilamellar vesicles, can be distinguished $[28,67$, 82]. This correlation allows for the comparison of BAL and stereological data. Thus, surfactant inactivation in ALI can be expressed as an increase in the SA/LA ratio [28] or as an increase in unilamellar vesicles relative to lamellar body-like forms and tubular myelin. Stereological assessment of intraalveolar surfactant has been performed in animal models of lung injury [40-43]. I/ $R$ injury studies have shown that the amount of surface active tubular myelin correlates with postischaemic lung function [42] and that intra-alveolar surfactant alterations are independent from the presence of intraalveolar oedema, therefore being not only a result but also a cause of intra-alveolar oedema formation [41]. This approach can also be used to analyse exogenous surfactant preparations (including their inactivation and its therapeutic prevention) in vitro [83].

Recommended parameters for the stereological analysis of intra-alveolar surfactant are surface fraction of alveolar epithelium covered with surfactant (SS(alvsurf/alvepi)), total intra-alveolar surfactant volume per lung ( $V$ (alvsurf, lung)), and volume fractions of its constituents, namely lamellar body-like forms $(V V$ (lbl/alvsurf) $)$, tubular myelin $(V V$ (tm/alvsurf)), multilamellar vesicles $(V V(\mathrm{mv} / \mathrm{alvsurf}))$ and unilamellar vesicles ( $V$ V(uv/alvsurf)) (table 1). 


\section{Analysis of intracellular surfactant}

In the analysis of intracellular surfactant, lamellar bodies are seen as the morphological equivalent of the intracellular surfactant pool. This approach has been used in human lungs [84] and in various animal models [85, 86]. In I/R injury, intraalveolar surfactant alterations, and thus a loss of surface-active surfactant forms in the alveoli, are associated with a decreased intracellular surfactant pool due to a decrease in the number of lamellar bodies per type II cell, indicating a compensatory increase in lamellar body secretion [85].

Recommended parameters for the stereological analysis of intracellular surfactant are the total lamellar body volume per lung $(V(\mathrm{lb}$, lung $))$ and per type II cell $(V(\mathrm{lb}$, type II) $)$, number of lamellar bodies per type II cell ( $N(\mathrm{lb}$, type II)), number-weighted mean lamellar body size $(\bar{v} N(\mathrm{lb}))$ and volume-weighted mean lamellar body size $\bar{v} V(\mathrm{lb}))$ (table 1$)$.

\section{CONCLUSIONS}

Stereology is a set of accurate and efficient methods for the quantitative characterisation of the physical properties of biological objects based on sampling rules and microscopic measurements. It thus provides lung researchers with tools that are essential to obtain valid data for the quantitative assessment of the ultrastructural alterations that are seen in acute lung injury. Physician-scientists should be encouraged to apply stereology to better understand lung structure and function in health and disease and, finally, to find better treatment options for patients with lung diseases.

\section{ACKNOWLEDGEMENTS}

The author would like to acknowledge the cooperation of many friends and colleagues over the years, several of whom contributed to the present issue of the European Respiratory Review. Many thanks to B. Krieger for her help with the illustrations.

\section{REFERENCES}

1 Weibel ER. Stereological Methods: Practical Methods for Biological Morphometry. New York, Academic Press, 1979.

2 Gundersen HJG, Bendtsen TF, Korbo L, et al. Some new, simple and efficient stereological methods and their use in pathological research and diagnosis. APMIS 1988; 96: 379-394.

3 Gundersen HJG, Bagger P, Bendtsen TF, et al. The new stereological tools: disector, fractionator, nucleator and point sampled intercepts and their use in pathological research and diagnosis. APMIS 1988; 96: 857-881.

4 Cruz-Orive LM, Weibel ER. Recent stereological methods for cell biology: a brief survey. Am J Physiol Lung Cell Mol Physiol 1990; 258: L148-L156.

5 Mayhew TM. The new stereological methods for interpreting functional morphology from slices of cells and organs. Exp Physiol 1991; 76: 639-665.

6 Howard CV, Reed MG. Unbiased Stereology. Threedimensional Measurement in Microscopy. 2nd Edn. Oxford, Bios, 2005.

7 Nyengaard JR, Gundersen HJG. Sampling for stereology in lungs. Eur Respir Rev 2006; 15: 107-114.
8 Ochs M. A brief update on lung stereology. J Microsc 2006 222: 188-200.

9 Weibel ER, Hsia CCW, Ochs M. How much is there really? Why stereology is essential in lung morphometry. J Appl Physiol 2007; 102: 459-467.

10 Ashbaugh DG, Bigelow DB, Petty TL, Levine BE. Acute respiratory distress in adults. Lancet 1967; 2: 319-323.

11 Bernard GR, Artigas A, Brigham KL, et al. The American European Consensus Conference on ARDS: definitions, mechanisms, relevant outcomes, and clinical trial coordination. Am J Respir Crit Care Med 1994; 149: 818-824.

12 Ware LB, Matthay MA. The acute respiratory distress syndrome. New Engl J Med 2000; 342: 1334-1349.

13 Matthay MA, Zimmerman GA, Esmon C, et al. Future research directions in acute lung injury. Am J Respir Crit Care Med 2003; 167: 1027-1035.

14 De Perrot M, Liu M, Keshavjee S. Ischemia-reperfusioninduced lung injury. Am J Respir Crit Care Med 2003; 167: 490-511.

15 Van Raemdonck D, Strüber M, Venuta F, Vlasselaers D, Wisser W, Erasmus ME. Strategies in the prevention and the treatment of ischaemia-reperfusion injury after lung transplantation. Eur Respir Mon 2004; 29: 66-88.

16 Christie JD, Carby M, Bag R, Corris P, Hertz M, Weill D. Report of the ISHLT working group on primary lung graft dysfunction part II: definition. A consensus statement of the International Society for Heart and Lung Transplantation. J Heart Lung Transplant 2005; 24: 1454-1459.

17 Rubenfeld GD, Caldwell E, Peabody E, et al. Incidence and outcomes of acute lung injury. New Engl J Med 2005; 353: 1685-1693.

18 MacCallum NS, Evans TW. Epidemiology of acute lung injury. Curr Opin Crit Care 2005; 11: 43-49.

19 Lewandowski K, Lewandowski M. Epidemiology of ARDS. Minerva Anestesiol 2006; 72: 473-477.

20 Bachofen M, Weibel ER. Alterations of the gas exchange apparatus in adult respiratory insufficiency associated with septicemia. Am Rev Respir Dis 1977; 116: 589-615.

21 Anderson WR, Thielen K. Correlative study of adult respiratory distress syndrome by light, scanning, and transmission electron microscopy. Ultrastruct Pathol 1992; 16: 615-628.

22 Albertine KH. Histopathology of pulmonary edema and the acute respiratory distress syndrome. In: Matthay MA, Ingbar DH, eds. Pulmonary Edema. New York, Marcel Dekker, 1998; pp. 37-83.

23 Tomashefski JF Jr. Pulmonary pathology of the acute respiratory distress syndrome. Diffuse alveolar damage. In: Matthay MA, ed. Acute Respiratory Distress Syndrome. New York, Marcel Dekker, 2003; pp. 75-114.

24 Knight PR, Rotta AT. Acute lung injury: etiologies and basic features. In: Notter RH, Finkelstein JN, Holm BA, eds. Lung Injury. Mechanisms, Pathophysiology, and Therapy. Boca Raton, Taylor and Francis, 2005; pp. 67-109.

25 Menezes SLS, Bozza PT, Castro Faria Neto HC, et al. Pulmonary and extrapulmonary acute lung injury: inflammatory and ultrastructural analyses. J Appl Physiol 2005; 98 : 1777-1783.

26 Piantadosi CA, Schwartz DA. The acute respiratory distress syndrome. Ann Intern Med 2004; 141: 460-470. 
27 Mendez JL, Hubmayr RD. New insights into the pathology of acute respiratory failure. Curr Opin Crit Care 2005; 11 : 29-36.

28 Lewis JF, Novick RJ, Veldhuizen RAW. Surfactant in Lung Injury and Lung Transplantation. New York, Springer, 1997.

29 Putman E, Van Golde LMG, Haagsman HP. Toxic oxidant species and their impact on the pulmonary surfactant system. Lung 1997; 175: 75-103.

30 Baker CS, Evans TW, Randle BJ, Haslam PL. Damage to surfactant-specific protein in acute respiratory distress syndrome. Lancet 1999; 353: 1232-1237.

31 Notter RH. Lung Surfactants. Basic Science and Clinical Applications. New York, Marcel Dekker, 2000.

32 Günther A, Ruppert C, Schmidt R, et al. Surfactant alteration and replacement in acute respiratory distress syndrome. Respir Res 2001; 2: 353-364.

33 Lewis JF, Veldhuizen R. The role of exogenous surfactant in the treatment of acute lung injury. Annu Rev Physiol 2003; 65: 613-642.

34 Wang Z, Holm BA, Matalon S, Notter RH. Surfactant activity and dysfunction in lung injury. In: Notter $\mathrm{RH}$, Finkelstein JN, Holm BA, eds. Lung Injury. Mechanisms, Pathophysiology, and Therapy. Boca Raton, Taylor and Francis, 2005; pp. 297-352.

35 Finkelstein JN, O'Reilly MA, Holm BA, Chess PR, Notter RH. Cell and animal models of lung injury. In: Notter RH, Finkelstein JN, Holm BA, eds. Lung Injury. Mechanisms, Pathophysiology, and Therapy. Boca Raton, Taylor and Francis, 2005; pp. 353-404.

36 Montaner JSG, Tsang J, Evans KG, et al. Alveolar epithelial damage. A critical difference between high pressure and oleic acid-induced low pressure pulmonary edema. J Clin Invest 1986; 77: 1786-1796.

37 Bachofen H, Weibel ER. Structure-function relationships in the pathogenesis of pulmonary edema. In: Weir EK, Reeves JT, eds. Pulmonary Edema. Armonk, Futura, 1998; pp. 17-33.

38 Martin TR. Neutrophils and lung injury: getting it right. J Clin Invest 2002; 110: 1603-1605.

39 Parker JC, Townsley MI. Evaluation of lung injury in rats and mice. Am J Physiol Lung Cell Mol Physiol 2004; 286: L231-L246.

40 Fehrenbach H, Brasch F, Uhlig S, et al. Early alterations in intracellular and alveolar surfactant of the rat lung in response to endotoxin. Am J Respir Crit Care Med 1998; 157: 1630-1639.

41 Ochs M, Nenadic I, Fehrenbach A, et al. Ultrastructural alterations in intraalveolar surfactant subtypes after experimental ischemia and reperfusion. Am J Respir Crit Care Med 1999; 160: 718-724.

42 Ochs M, Fehrenbach H, Nenadic I, et al. Preservation of intraalveolar surfactant in a rat lung ischaemia/reperfusion injury model. Eur Respir J 2000; 15: 526-531.

43 Fehrenbach A, Ochs M, Wahlers T, et al. Beneficial effect of lung preservation is related to ultrastructural integrity of tubular myelin after experimental ischemia and reperfusion. Am J Respir Crit Care Med 2000; 161: 2058-2065.

44 Bachofen H, Ammann A, Wangensteen D, Weibel ER. Perfusion fixation of lungs for structure-function analysis: credits and limitations. J Appl Physiol 1982; 53: 528-533.
45 Weibel ER. Morphometric and stereological methods in respiratory physiology, including fixation techniques. In: Otis AB, ed. Techniques in the Life Sciences. Techniques in Respiratory Physiology, part 1. County Clare, Elsevier, 1984; pp. 1-35.

46 Gil J. Histological preservation and ultrastructure of alveolar surfactant. Annu Rev Physiol 1985; 47: 753-763.

47 Gil J. Controlled and reproducible fixation of the lung for correlated studies. In: Gil J, ed. Models of Lung Disease. Microscopy and Structural Methods. New York, Marcel Dekker, 1990; pp. 3-22.

48 Bachofen H, Schürch S, Michel RP, Weibel ER. Experimental hydrostatic pulmonary edema in rabbit lungs: morphology. Am Rev Respir Dis 1993; 147:989-996.

49 Fehrenbach H, Ochs M. Studying lung ultrastructure. In: Uhlig S, Taylor AE, eds. Methods in Pulmonary Research. Basel, Birkhäuser, 1998; pp. 429-454.

50 Scherle W. A simple method for volumetry of organs in quantitative stereology. Mikroskopie 1970; 26: 57-60.

51 Michel RP, Cruz-Orive LM. Application of the Cavalieri principle and vertical sections method to lung: estimation of volume and pleural surface area. J Microsc 1988; 150: 117-136.

52 Yan X, Polo Carbayo JJ, Weibel ER, Hsia CCW. Variation of lung volume after fixation when measured by immersion or Cavalieri method. Am J Physiol Lung Cell Mol Physiol 2003; 284: L242-L245.

53 Staub NC, Nagano H, Pearce ML. Pulmonary edema in dogs, especially the sequence of fluid accumulation in lungs. J Appl Physiol 1967; 22: 227-240.

54 Staub NC. Pulmonary edema. Physiol Rev 1974; 54: 678-811.

55 Mühlfeld C, Müller K, Pallesen LP, et al. Impact of preservation solution on the extent of blood-air barrier damage and edema formation in experimental lung transplantation. Anat Rec 2007; 290: 491-500.

56 Fehrenbach H, Schepelmann D, Albes JM, et al. Pulmonary ischemia/reperfusion injury: a quantitative study of structure and function in isolated heart-lungs of the rat. Anat Rec 1999; 255: 84-99.

57 Fehrenbach A, Fehrenbach H, Wittwer T, Ochs M, Wahlers T, Richter J. Evaluation of pulmonary edema: stereological versus gravimetrical analysis. Eur Surg Res 2001; 33: 270-278.

58 Ochs M, Fehrenbach H, Richter J. Ultrastructure of canine type II pneumocytes during hypothermic ischemia of the lung: a study by means of conventional and energy filtering transmission electron microscopy. Anat Rec 2001; 263: 118-126.

59 Fehrenbach H. Alveolar epithelial type II cell: defender of the alveolus revisited. Respir Res 2001; 2: 33-46.

60 Clegg GR, Tyrrell C, McKechnie CR, Beers MF, Harrison D, McElroy MC. Coexpression of RTI40 with alveolar epithelial type II cell proteins in lungs following injury: identification of alveolar intermediate cell types. Am J Physiol Lung Cell Mol Physiol 2005; 289: L382-L390.

61 Elias H. Identification of structure by the common-sense approach. J Microsc 1972; 95: 59-68.

62 Weibel ER. The Pathway for Oxygen. Cambridge, Harvard University Press, 1984. 
63 Maina JN, West JB. Thin and strong! The bioengineering dilemma in the structural and functional design of the blood-gas barrier. Physiol Rev 2004; 85: 811-844.

64 Gehr P, Bachofen M, Weibel ER. The normal human lung: ultrastructure and morphometric estimation of diffusion capacity. Respir Physiol 1978; 32: 121-140.

65 Wright JR. Immunomodulatory functions of surfactant. Physiol Rev 1997; 77: 931-962.

66 Hawgood S. Surfactant: Composition, structure, metabolism. In: Crystal RG, West JB, Weibel ER, Barnes PJ, eds. The Lung: Scientific Foundations. 2nd Edn. New York, Lippincott-Raven, 1997; pp. 557-572.

67 Griese M. Pulmonary surfactant in health and human lung diseases: state of the art. Eur Respir J 1999; 13: 1455-1476.

68 Wright JR. Immunoregulatory functions of surfactant proteins. Nat Rev Immunol 2005; 5: 58-68.

69 Mason RJ, Shannon JM. Alveolar type II cells. In: Crystal RG, West JB, Weibel ER, Barnes PJ, eds. The Lung: Scientific Foundations, 2nd Edn. New York, LippincottRaven, 1997; pp. 543-555.

70 Schmitz G, Müller G. Structure and function of lamellar bodies, lipid-protein complexes involved in storage and secretion of cellular lipids. J Lipid Res 1991; 32: 1539-1570.

71 Weaver TE, Na CL, Stahlman M. Biogenesis of lamellar bodies, lysosome-related organelles involved in storage and secretion of pulmonary surfactant. Semin Cell Dev Biol 2002; 13: 263-270.

72 Dietl P, Haller T. Exocytosis of lung surfactant: from the secretory vesicle to the air-liquid interface. Annu Rev Physiol 2005; 67: 595-621.

73 Lewis JF, Jobe AH. Surfactant and the adult respiratory distress syndrome. Am Rev Respir Dis 1993; 147: 218-233.

74 Pison U, Böck JC, Pietschmann S, Veit S, Slama K. The adult respiratory distress syndrome: pathophysiological concepts related to the pulmonary surfactant system. In: Robertson B, Taeusch HW, eds. Surfactant Therapy for Lung Disease. New York, Marcel Dekker, 1995; pp. 169-197.

75 Jobe AH, Ikegami M. Surfactant and acute lung injury. Proc Assoc Am Physicians 1998; 110: 489-495.
76 Creuwels LAJM, Van Golde LMG, Haagsman HP. The pulmonary surfactant system: biochemical and clinical aspects. Lung 1997; 175: 1-39.

77 Costabel U. Bronchoalveolar lavage: a standardized procedure or a technical dilemma? Eur Respir J 1991; 4: 776-777.

78 Baughman RP. The uncertainties of bronchoalveolar lavage. Eur Respir J 1997; 10: 1940-1942.

79 Haslam PL, Postle AD, Raymondos K, Baker CS. Measurement of pulmonary surfactant components and function in bronchoalveolar lavage fluid. Eur Respir Rev 1999; 9: 43-69.

80 Tiroke AH, Bewig B, Haverich A. Bronchoalveolar lavage in lung transplantation. State of the art. Clin Transplant 1999; 13: 131-157.

81 Ochs M. Pulmonary surfactant preservation in experimental and clinical lung transplantation. In: Pandalai SG, ed. Recent research developments in respiratory and critical care medicine. Trivandrum, Research Signpost, 2001; pp. 59-81.

82 Gross NJ. Extracellular metabolism of pulmonary surfactant: the role of a new serine protease. Annu Rev Physiol 1995; 57: 135-150.

83 Ochs M, Schüttler M, Stichtenoth G, Herting E. Morphological alterations of exogenous surfactant inhibited by meconium can be prevented by dextran. Respir Res 2006; 7, 86: 1-8.

84 Ochs M, Nyengaard JR, Waizy $H$, Wahlers T, Gundersen HJG, Richter J. Alveolar type II cells and the intracellular surfactant pool in the human lung - a stereological approach. Am J Respir Crit Care Med 2001; 163: A731.

85 Waizy H, Fehrenbach H, Wahlers T, Richter J, Ochs M. Alterations in intracellular surfactant of the rat lung in response to ischemia-reperfusion injury. Am J Respir Crit Care Med 2001; 163: A732.

86 Fehrenbach A, Bube C, Hohlfeld JM, et al. Surfactant homeostasis is maintained in vivo during keratinocyte growth factor-induced rat lung type II cell hyperplasia. Am J Respir Crit Care Med 2003; 167: 1264-1270. 